Manuscript ID

ZUMJ-1906-1264

DOI

10.21608/zumj.2019.13318.1264

ORIGINAL ARTICLE

\title{
Povidone-iodine in a Pleurodesis: is it Safe and Effective in the Management of Malignant Pleural Effusion?
}

\author{
Essam Saad Abdel-Wahed, Ehab Sobhy, Giuma Ali Giuma Elmarghni,Walid Galal \\ Elghamry: \\ Cardiothoracic Surgery Department, Faculty of Medicine - Zagazig University, Sharkia Egypt
}

Corresponding Author:
Giuma Ali Giuma
Elmarghni
dr_jumaaali @yahoo.com

Submit Date 2019-07-23

Accept Date 2019-09-14
Background: The presence of malignant cells in pleural fluid or pleural tissue is called malignant pleural effusion (MPE). Lung cancer, breast, ovary, and lymphoma are responsible for malignant pleural effusion by more than $75 \%$. Pleurodesis is a common method for managing malignant pleural effusion to generate a symphysis between parietal and visceral pleura.

Aim and objectives: The aim of this study is to evaluate the safety, efficacy and the success rate of $10 \%$ povidone-iodine in pleurodesis procedure through thoracostomy by conducting the objectives which were assessment of radiological outcome after using of povidone-iodinee as a chemical pleurodesis, assessment the adverse event and clinical outcome after using of povidoneiodinee as a chemical pleurodesis and evaluation the effect of povidone-iodine on thyroid function test.

patients and methods: this is randomized clinical trial, was carried out on 24 cases at Cardiothoracic Surgery Department, Zagazig and Tripoli University Hospitals, all patients, who underwent pleural drainage and received bedside pleurodesis with $10 \%$ povidone-iodine, Pleurodesis efficacy was defined in three response levels, 1)symptomatic improvement of dyspnea with complete radiographic resolution of the pleural effusion till the end of follow up as "complete response" 2) symptomatic improvement with recurrent pleural effusion that did not need additional thoracentesis as "partial response" ,and 3) recurrent pleural effusion that needs further thoracentesis as "treatment failure" . Results The results revealed that Early response was $70.8 \%$ complete response, partial response in $25 \%$, and failure $4.2 \%$, the major complication was need of analgesia, regarding follow up successes (complete and partial) $87.5 \%$ and failure $12.5 \%$.

Conclusions: Povidone-iodine is shown to be a safe and effective agent with few adverse effects in pleurodesis of patients with malignant pleural effusion can be used as a low cost and accessible alternative to other chemical sclerosing agents.

Keywords: Pleurodesis, povidone-iodine, Malignant pleural effusion

\section{INTRODUCTION}

The presence of malignant cells in pleural fluid or pleural tissue is called malignant pleural effusion (MPE). Lung cancer represents the most common source of malignant pleural effusion with(30 percent), followed by breast cancer, ovarian cancer, lymphoma, and gastric cancer. ${ }^{[1,2]}$.

Poor prognostic cancers are generally linked with malignant pleural effusion. One of the most prevalent symptoms of malignant pleural effusion is dyspnea on exertion and respiratory distress ${ }^{[3,4]}$. 
Chemotherapy may limit pleural effusion and alleviate symptoms of pleural malignancy in certain malignancies, such as small lung carcinoma and lymphoma. ${ }^{[5]}$.

in the event of the chemotherapy failure and the re-accumulation of fluid in the pleural cavity, the recurrent thoracentesis, pleurodesis, pleurectomy, and indwelling pleural catheter can control malignant pleural effusion ${ }^{[6]}$.

Pleurodesis is a standard procedure for the control of malignant pleural effusion that produces symphysis between two layers of pleura to prevent fluid buildup in a pleural cavity using various chemical agents such as tetracycline, doxycycline, bleomycin, talc, and povidone-iodine[betadine] ${ }^{[4,7]}$.

Efficacy evaluation of particular sclerosing agents was difficult, as reported studies evaluated a restricted number of patients, used conflicting success criteria and used various pleurodesis methods ${ }^{[8]}$.

Povidone-iodine is a broad-spectrum and lowcost antiseptic agent commonly accessible in many forms. ${ }^{[7,6]}$.

The issue is the decision of the sclerosing agent, which is determined not only by the agent's efficacy, but also by the agent's cost, accessibility, safety, ease of administration and, number of administrations to provide a complete response. ${ }^{[1]}$.

\section{PATIENTS AND METHODS}

This is randomized clinical trial, was carried out on 24 cases at Cardiothoracic Surgery Department, Zagazig and Tripoli University Hospitals, all patients, who underwent pleural drainage and received bedside pleurodesis with $10 \%$ povidone-iodine, The efficacy of pleurodesis was classified in three levels of response. 1)symptomatic improvement of dyspnea with complete radiographic resolution of the pleural effusion till the end of follow up as "complete response" 2) symptomatic improvement with recurrent pleural effusion that did not need additional thoracentesis as "partial response" ,and 3) recurrent pleural effusion that needs further thoracentesis as"treatment failure" .
Written informed consent was obtained from all participants and the study was approved by the research ethics committee of the Faculty of Medicine, Zagazig University. The work has been carried out in accordance with The Code of Ethics of the World Medical Association (Declaration of Helsinki) for studies involving humans.

\section{Inclusion criteria:}

Recurrent malignant pleural effusion.

Evidence of full lung expansion after fluid drainage.

\section{Exclusion criteria:}

Patients with a history of cardiac disease.

Loculated effusions.

Abnormal thyroid function test.

Incomplete lung re-expansion after chest tube or tunneled catheter insertion.

The participants were chosen by systematic random sampling from Patients admitted at the Cardiothoracic Surgery Department.

Methods: The followings were done for all patients:

(1) Full history taking in the form of:

a. Personal history (name, age, sex, residence, occupation, special habits)

b. History of present illness

c. History of other diseases or associated comorbidities (Diabetes Mellitus, Hypertension, cardiac, thyroid dysfunction patients)

f. History of drug intake.

d. History of malignancy.

e. Family history of any chest or malignant diseases

(2) Full clinical examination including:

a) General examination: search for signs of heart failure, renal failure, malignancy or any others causes of pleural effusion

b) Local chest examination: for signs of pleural effusion :

(3) Plain chest X-ray(postero-anterior view): to assess the amount of pleural fluid and is it free or encysted.

(4) Routine haematologic investigations: - Complete blood picture (CBC). 
-Thyroid function test

-Liver function tests \& Kidney function tests.

- Bleeding \& clotting time, prothrombin time concentration \& INR.

B. Operative technique:

Surgical technique

Patients admitted to the Department of Cardiothoracic Surgery because of symptomatic malignant pleural effusion.

All patients had confirmed malignant pleural effusion provided by the positive result of pleural effusion cytology or pleural biopsy.

In this study, thyroid function testing was performed before the procedure, due to the possible systemic intake of iodine in povidoneiodine and severity of thyroid disease. Therefore, patients with disturbance of thyroid function were prohibited in the study.

The serum concentrations of (TSH, T3, and T4) have been evaluated pre and post pleurodesis to assess the effects of povidone-iodine on the thyroid gland.

An abnormal test of thyroid functions following the procedure may be indicators of iodin action on the thyroid gland related to povidone-iodine pleurodesis.

- Lidocaine (3 mg/kg; max. $250 \mathrm{mg}$ ) was injected intrapleural right before sclerosing, premedication was considered to alleviate anxiety and pain (pethidine $50 \mathrm{mg}$ iv/im)

- A $20 \mathrm{~mL}$ admixture with 10 percent povidoneiodine solution and $80 \mathrm{~mL}$ of normal saline was instilled into pleural space via tunnels or intercostal tube, and tube clamped for 1-hour.

- The tunnel catheter or tube removed within 24-48 hours from sclerosing administration in the absence of excessive drainage ( $>250$ $\mathrm{mL} /$ day) and no fluid collection obtained in a chest $\mathrm{x}$-ray.

\section{RESULTS}

Among the 24th studied patients, Dyspnea was found in 22 patients (91.7\%), cough in 11 patients $(54.2 \%)$ and chest pain in 6 patients (25\%). (Table.1)

The highest cancer type, distributed among the studied patients was breast cancer representing $29.2 \%$ followed by lung $25 \%$ and lymphoma 20.8\%. (Table.2)

The major complications or adverse effects of Pleurodesis were the need of analgesia which needed in $(62.5 \%)$ of studied patients, followed by fever $(25 \%)$, with no change in the thyroid function test. other complications were nausea and dizziness. (Table.3)

The response to Pleurodesis was $70.8 \%$ complete response, partial in $25 \%$ and failure $4.2 \%$, regarding the follow-up successes (complete and partial) $87.5 \%$ and failure 12.5 $\%$. ( table.4).(Figure.1)(Figure.2)(Figure.3).

\section{Captions of patient's cases:}

(Figure.1)(Figure.2)(Figure.3)

A 40-year-old gentleman, presented to causality with history of progressive shortness of breath over one month, with no history of cough or chest pain, he was diagnosed with lymphoma, and patient gave a history of multiple thoracentesis, otherwise, there was no history of any significant comorbidities. On examination he was dyspneic and tachypneic and air entry was markedly diminished on the right side of the chest, oxygen saturation on room air was 88 $\%$, chest $\mathrm{x}$-ray showed right massive sided pleural effusion, thoracostomy by pleural catheter was inserted and total amount of $3000 \mathrm{cc}$ serous fluid was drained, pleurodesis by povidone-iodine was applying with no adverse events, after one day patient had been discharged and catheter removed and he followed after one month with no history of dyspnea or reaccumulation of pleural fluid on chest x-ray. 
Table (1): Symptoms distribution among studied groups

\begin{tabular}{|l|l|l|l|}
\hline Dyspnea & No & N & $\%$ \\
\hline \multirow{2}{*}{ Cough } & Yes & 22 & 8.4 \\
\hline Chest pain & No & 11 & 91.7 \\
\hline & Yes & 13 & 45.8 \\
\hline & No & 18 & $\mathbf{5 4 . 2}$ \\
\hline & Yes & 6 & $\mathbf{7 5 . 0}$ \\
\hline & Total & 24 & $\mathbf{2 5 . 0}$ \\
\hline
\end{tabular}

Table (2): Cancer type distribution

\begin{tabular}{|l|l|l|l|}
\hline Cancer type & N & $\%$ \\
\hline Lung & 7 & 29.2 \\
\hline Lymphoma & 6 & 25.0 \\
\hline Colon & 5 & 20.8 \\
\hline Ovary & 2 & 8.3 \\
\hline Mesothelioma & 2 & $\mathbf{8 . 3}$ \\
\hline Prostate & 1 & 4.2 \\
\hline Total & 1 & $\mathbf{4 . 2}$ \\
\hline
\end{tabular}

Table (3): Adverse effects and Complication distribution

\begin{tabular}{|c|c|c|c|}
\hline & & $\mathbf{N}$ & $\%$ \\
\hline \multirow[t]{2}{*}{ Fever } & No & 18 & 75.0 \\
\hline & Yes & 6 & 25.0 \\
\hline Thyroid changes & No changes & 24 & 100 \\
\hline \multirow[t]{5}{*}{ Other complication } & No & 12 & 50.0 \\
\hline & Dizziness & 2 & 8.3 \\
\hline & Dyspnea & 1 & 4.2 \\
\hline & Nausea & 8 & 23.3 \\
\hline & Nausea and dizziness & 1 & 4.2 \\
\hline \multirow[t]{3}{*}{ Need analgesia } & Complete & 8 & 33.3 \\
\hline & No & 9 & 37.5 \\
\hline & Total & 24 & 100.0 \\
\hline
\end{tabular}


Table (4): Response and follow up distribution

\begin{tabular}{|l|l|l|l|}
\hline \multirow{2}{*}{ Response to treatment } & Complete & No & $\%$ \\
\hline & Partial & $\mathbf{1 7}$ & $\mathbf{7 0 . 8}$ \\
\hline & Failure & $\mathbf{6}$ & $\mathbf{2 5 . 0}$ \\
\hline & Complete & $\mathbf{8}$ & $\mathbf{4 . 2}$ \\
\hline & Failure & 3 & 33.3 \\
\hline \multirow{3}{*}{ Follow up after one month } & Partial & 13 & 12.5 \\
\hline & Success & 21 & $\mathbf{5 4 . 2}$ \\
\hline & failed & 3 & 87.5 \\
\hline & Total & 24 & 12.5 \\
\hline
\end{tabular}

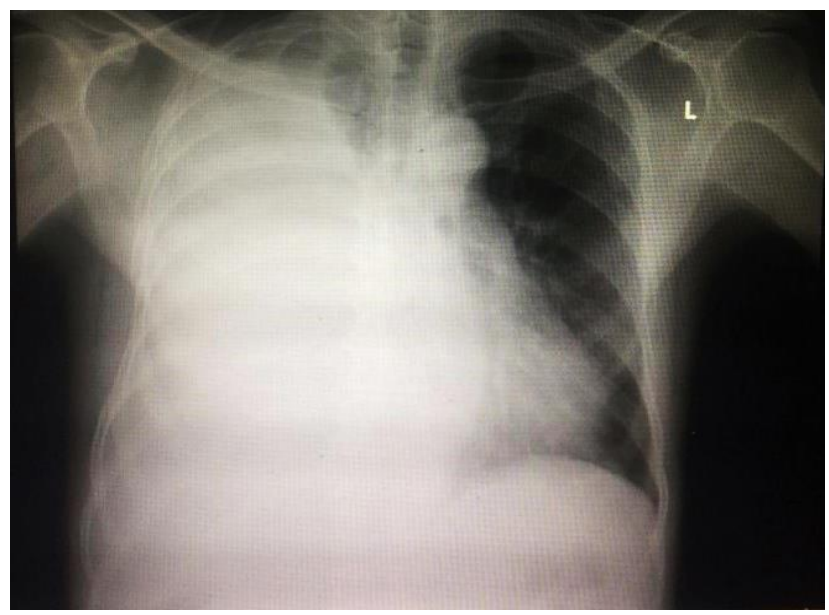

(Figure.1: chest X-ray PA view for 40yrs old patient with right sided massive pleural effusion)

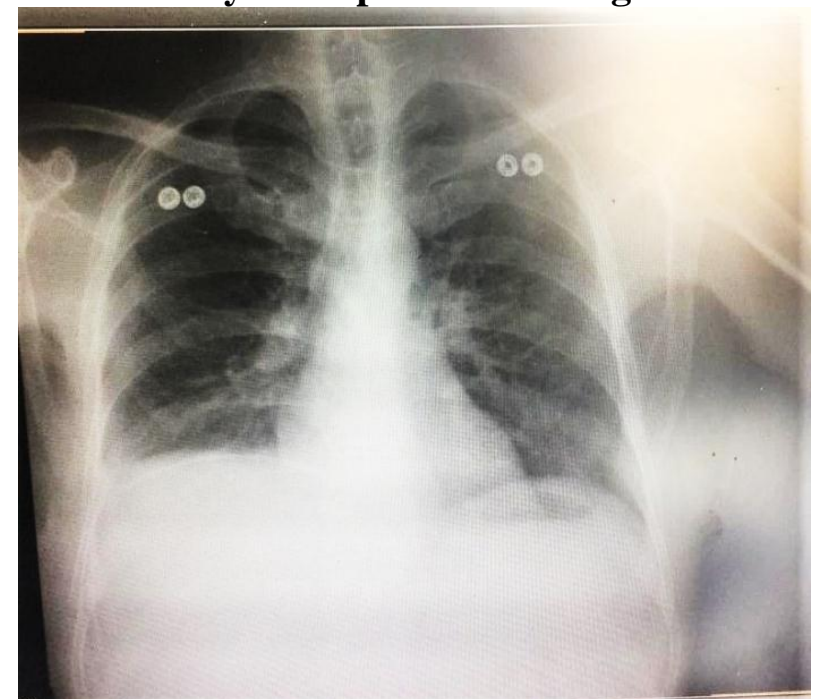

(Figure.2: chest X-ray PA view for 40yrs old patient with right sided massive pleural effusion; Post pleurodesis) 


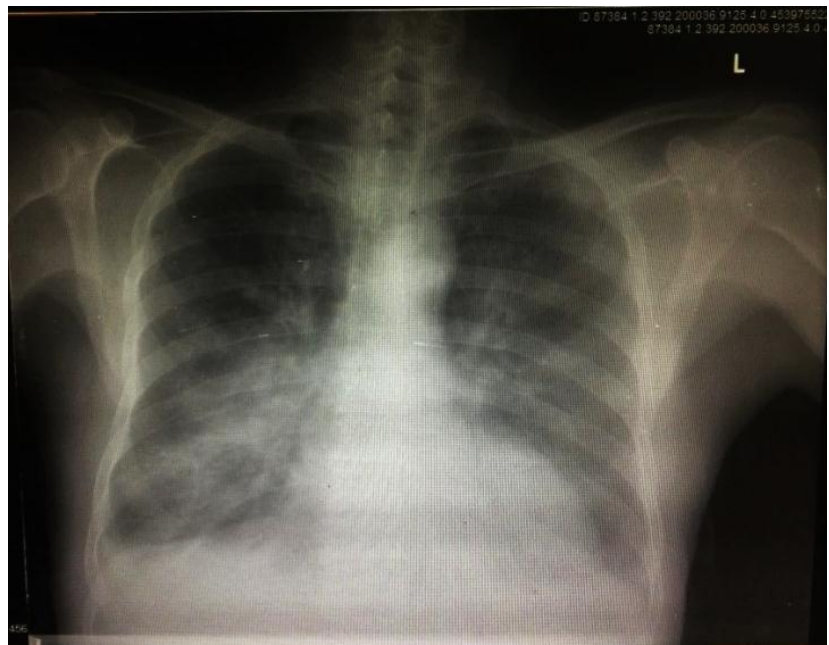

(Figure.3: chest X-ray PA view for 40yrs old patient with right sided massive pleural effusion, Follow up after one month)

\section{DISCUSSION}

Malignant pleural effusion (MPE) occurs in advanced stages and often has a poor prognosis [9]. Most patients with MPE are symptomatic and exertional dyspnea is the most frequent symptom [10] Most patients receive chemotherapy or local therapy to ease symptoms like dyspnea, cough and chest pain and enhance the quality of life. If main malignant diseases are sensitive to chemo such as small cell lung carcinoma and lymphoma, systemic chemotherapy can regulate the pleural effusion. However, when pleural effusion recurs or recurrent following chemotherapy, refractory MPE treatment involves local therapy procedures as thoracentesis, pleurodesis, or pleurectomy. ${ }^{[11]}$ Injection into pleural space of sclerosing agents (pleurodesis) is a frequent operation for MPE management ${ }^{[11]}$ For 70 years a lot of substances have been injecting into the pleural cavity such as antineoplastic (e.g., mustard nitrogen, bleomycin), tetracycline derivatives, talc, erythromycin, nitrate silver, and Povidone-iodine to create pleurodesis [12]. The purpose of the current prospective study was to research the efficacy and safety of pleurodesis with povidone-iodine, as an inexpensive option for local pleural effusion management in patients with MPE admitted in Cardiothoracic Surgery Department, of Zagazig and Tripoli University
Hospitals during November 2018-May 2019. Povidone-iodine (topical solution, topical ointment, shampoo, surgical scrub) is an antiseptic agent in a different design. In the present research, povidone-iodine is used in the shape of a topical 10\%, containing $1 \%$ effective iodine. And Povidone-iodine is a good alternative to talc pleurodesis with a rate of efficacy of approx. 90\% and with a small number of complications ${ }^{[4]}$

\section{1-Baseline characteristics of the studied groups:}

Our study demonstrated that the Age of the studied group was $54.08 \pm 13.37$ with minimum 25 and maximum of 72 years, regarding sex male were $45.8 \%$ and female were $54.2 \%$.

(Godazandeh et al., 2011) [12] Who conducted a study from October 2008 to June 2011, 42 patients were admitted to the Department of Thoracic Surgery Mazandaran University of Medical Sciences demonstrated that the mean age of patients was $64.7 \pm 8.4$ [49$80]$ years. Fifteen patients $(41.6 \%)$ were men and $22(58.3 \%)$ were women.

A study by (Arfa, 2014) ${ }^{[13]}$ was carried out in the period between July 2013 and April 2014 in the chest departments of Bab Elsheria University Hospital. Thirty patients with malignant pleural effusion were included in his study. Patients divided into 2 groups fifteen patients in each group. Group I underwent 
pleurodesis by Povidone-iodine and group II underwent pleurodesis by bleomycin, demonstrated that the age of the patients in the studied groups ranged from 45 to 75 years old, 20 patients $(60 \%)$ were males and $10(30 \%)$ were females.

\section{2- Clinical characteristics of the studied groups:}

Our study demonstrated that Dyspnea was in $91.7 \%$ and cough in $54.2 \%$ and chest pain in $25 \%$.

The highest type of cancer was breast cancer in $(29.2 \%)$ of patients followed by lung $(25 \%)$ and lymphoma 20.8\%. (Arfa, 2014) [13] demonstrated that presenting symptoms were dyspnea in 17 patients $(56.7 \%)$ and chest pain in 13 patients $(43.3 \%)$.

In contrast to (Godazandeh et al., 2011) ${ }^{[12]}$ who found that lung cancer $(\mathrm{n}=19,52.7 \%)$ was the most common primary diseases, followed by breast cancer $(\mathrm{n}=8,22.2 \%)$, ovarian cancer $(\mathrm{n}=5,13.8 \%)$, gastric cancer $(\mathrm{n}=2,5.5 \%)$ and $(\mathrm{n}=2,5.5)$ with an unknown origin.

3-Characters of effusion and associated complications related to pleurodesis:

Our study showed that the involved side was the right side in $70.8 \%$ and left was in $29.2 \%$.

(Godazandeh et al., 2011) ${ }^{[12]}$ demonstrated that in 21 patients $(58.3 \%)$ the involved side was the right side and, left side in 11 patients $(30.5 \%)$ and 4 patients $(11.1 \%)$ was bilateral Major complication or adverse effect was need of analgesia (mild pain) that treated with nonopioids, with $62.5 \%$ followed by fever $25 \%$, and no change in thyroid function was observed in all of the cases.

(Dias et al., 2015) ${ }^{[14]}$ Reported that the most frequent adverse event to pleurodesis was Pleuritic pain. It occurred in 33 patients (55\%) and was classified as severe pain in 11 of them (18\%). Pain has already been reported with Povidone-iodine and other sclerosing agents as a pleurodesis complication.

(Arfa, 2014) ${ }^{[13]}$ Stated that complications of pleurodesis were recorded immediately after the procedure until the discharge of the patients. in eleven cases $(73.3 \%)$ no complications were detected after Povidone-iodine pleurodesis, two cases $(13.3 \%)$ developed low-grade fever (37.537.8 ) ten hours after the procedure and responded to antipyretics and two cases (13.3\%) developed chest pain during pleurodesis and responded to analgesics.

(Yeginsu et al., 2007) ${ }^{[15]}$ Evaluated thyroid hormones 24 hours and 72 hours after Povidone-iodine pleurodesis in $12 \mathrm{MPE}$ patients. They found no difference over time in these hormone levels. The hormone concentrations are assessed on the 2nd and 30th day following pleurodesis, 5 patients developed subclinical hypothyroidism as diagnosed by their thyroid-stimulating hormone levels. Most of these hormone alterations were transitory and returned to normal values on the 30th day of analysis and, no medical treatment was necessary, And, according to the Common Terminology Criteria (CTCAE) classification for Adverse Events, such events were considered no serious events.

\section{4- Outcome and its relations of the studied groups:}

In our study the response was $70.8 \%$ complete, partial in $25 \%$ and failure in $4.2 \%$, the major complication was need of analgesic( mild pain), regard follows up successes (complete and partial) was $87.5 \%$ and failure $12.5 \%$.

(Arafa, 2014) ${ }^{[13]}$ Stated that 13 cases (86.7\%) showed a complete response in, while failure was found in 2 cases (13.3\%) with a success rate of $86.7 \%$.

(Godazandeh et al., 2011) ${ }^{[12]}$ Showed that 26 patients (72.2\%) and 7 patients (19.4\%) had complete and partial responses respectively, while 3 patients $(8.3 \%)$ failed in treatment.

(Agarwal et al. 2011) ${ }^{[16]}$ In a study of 37 patients of pleural effusion with povidoneiodine obtained a complete response rate of 86.5 percent.

In a review by (Agarwal et al., 2006) ${ }^{[1]}$ of the six research, 265 individuals had chemical pleurodesis of povidone-iodine and an average success rate was $90.6 \%$. Pleurodesis with povidone-iodine for recurrent pleural effusion 
in 157 patients and pneumothorax in 108 patients was performed in this meta-analysis.

(Olivares-Torres, et al. 2002) ${ }^{[17]}$ Who used povidone-iodine for pleurodesis in recurrent pleural effusion. The study was applied on 52 patients from 14 Hospital in Trjuana and Ensendow, Mexico during the period between September 1996 and June 2001, like patients in our study, none of the patients in their study had undergone prior attempt for pleurodesis with other agents. The method of pleurodesis in their study was similar to the method of pleurodesis in our study by injection $20 \mathrm{ml} \mathrm{10 \%}$ povidone-iodine $+80 \mathrm{ml}$ normal saline in one session intrapleurally. In their study, pleurodesis was performed through a chest tube in 12 patients $(23.1 \%)$. for the remaining 40 patients $(76.9 \%)$ thoracoscopy was performed to obtain pleural tissue for diagnostic purpose and povidone-iodine was instilled at the end of the procedure, while in our study pleurodesis was performed in all patients through the chest tube or pleural catheter, They achieved a complete response in 50 patients $(96.1 \%)$.

(Kelly-Garcia et al., 1997) ${ }^{[18]}$ Who reported the use of povidone-iodine for pleurodesis in 14 cases with malignant pleural effusion compared to 24 cases with malignant pleural effusion in our study? They achieved success in controlling effusion in 9 patients $(64.2 \%)$ while recurrence of effusion occurred in 5 patients $(35.8 \%)$.

Also, there was a significant difference between a successful outcome and older age, also between a successful outcome and a shorter hospital stay.

This was against what stated by (Godazandeh et al., 2011) ${ }^{[12]}$ who has no significant link between response to therapeutic therapy and certain changes such as primary malignancy $(\mathrm{P}=0.683)$, patient gender $(\mathrm{P}=0.721)$, age $(\mathrm{P}=0.758)$ and the side involved $(\mathrm{P}=0.978)$.

The results of this study suggest that povidoneiodine is a safe and effective agent with minor side effects in pleurodesis and treatment of malignant pleural effusion and proposed povidone-iodine as a proper, accessible, and low-cost alternative sclerosing agent.

\section{CONCLUSION}

Povidone-iodine is shown to be a safe and effective agent with few adverse effects in pleurodesis of patients with malignant pleural effusion and can be used as an accessible and low-cost alternative than other chemical sclerosing agents.

\section{RECOMMENDATIONS}

Based on our results we recommend using povidone-iodine as an alternative sclerosing agent in the management of malignant pleural effusion.

Thoracic surgeons and pulmonologist should keep in their mind the use of povidone-iodine because of it is simplicity, safety, the readily available and inexpensive method with a high success rate and low complications.

Conflict of interest: The authors declare no conflict of interest.

Funding sources: The authors have no funding to report.

\section{REFERENCES}

1- Agarwal, R.; Aggarwal, A. N.; Gupta, D.; \& Jindal, S. K. (2006). Efficacy and safety of iodopovidone in chemical pleurodesis: a meta-analysis of observational studies. Respiratory medicine, 100(11), 2043-2047.

2- Caglayan, B.; Torun, E.; Turan, D., Fidan, A., Gemici, C., Sarac, G., et al (2008). Efficacy of iodopovidone pleurodesis and comparison of smallbore catheter versus large-bore chest tube. Annals of surgical oncology, 15(9), 2594-2599. DOI: 10.1245/s10434-008-0004-1.

3-Chen H, Brahmer J. Management of malignant pleural effusion (2008). Current Oncology Rep 2008;10:287-93.

4- Godazandeh, G., Qasemi, N. H., Saghafi, M., Mortazian, M., \& Tayebi, P. (2013). Pleurodesis with povidone-iodine, as an effective procedure in management of patients with malignant pleural effusion. Journal of thoracic disease, 5(2), 141.

5-Muduly D, Deo S, Subi TS, Kallianpur A, Shukla. (2011). an update in the management of malignant pleural effusion. Indian J Palliate Care 2011; 17:98103.

6-Kahrom, H., Aghajanzadeh, M., Asgari, M. R., \& Kahrom, M. (2017). Efficacy and safety of povidone-iodine pleurodesis in malignant pleural effusions. Indian journal of palliative care, 23(1), 53.

7- Tummuru, V. R., Waghray, P., Rao, A. K., Reddy, K. V. R., Veena, V., Mathew, J. J., et al (2015). Effect of pleurodesis with $10 \%$ betadine in a tertiary care centre, mahabubnagar, telengana. Journal of 
evolution of medical and dental sciences-jemds, 4(42), 7332-7335.

8-Tsai, T. H., Wu, S. G., Chang, Y. L., Wu, C. T., Tsai, M. F., Wei, P. F., et al. (2012). Effusion immunocytochemistry as an alternative approach for the selection of first-line targeted therapy in advanced lung adenocarcinoma. Journal of Thoracic Oncology, 7(6), 993-1000.

9- Dixit, R., Agarwal, K. C., Gokhroo, A., Patil, C. B., Meena, M., Shah, N. S., et al. (2017). Diagnosis and management options in malignant pleural effusions. Lung India: official organ of Indian Chest Society, 34(2), 160.

10- Light, R. W (2007): Pleural Diseases, 5th Edition. Baltimore, Lippincott Williams \& Wilkins (pages: 8 - 347).

11-Bhatnagar, R., Kahan, B. C., Morley, A. J., Keenan, E. K., Miller, R. F., Rahman, N. M., et al. (2015). The efficacy of indwelling pleural catheter placement versus placement plus talc sclerosant in patients with malignant pleural effusions managed exclusively as outpatients (IPC-PLUS): study protocol for a randomized controlled trial. Trials, 16(1), 48.

12- Godazandeh, G., Qasemi, N. H., Saghafi, M., Mortazian, M., \& Tayebi, P. (2011). Pleurodesis with povidone-iodine, as an effective procedure in management of patients with malignant pleural effusion, 1-4. https://doi.org/10.3978/j.issn.20721439.2013.02.02.
13-Arfa, M. A. (2014). Comparative study of pleurodesis using iodopovidone and bleomycin in management of malignant pleural effusion.

14- Dias, J., Neto, A., Terra, M., Teixeira, M., Vianna, S., \& Manuel, P. (2015). Safety Profile of the Use of Iodopovidone for Pleurodesis in Patients with Malignant Pleural Effusion, 225, 369-375. https://doi.org/10.1159/000440727.

15- Yeginsu, A., Karamustafaoglu, A., Ozugurlu, F., \& Etikan, I. (2007). Iodopovidone pleurodesis does not effect thyroid function in normal adults. Interactive cardiovascular and thoracic surgery, 6(4), 563-564.

16- Agarwal, R., Paul, A. S., Aggarwal, A. N., Gupta, D., \& Jindal, S. K. (2011). A randomized controlled trial of the efficacy of cosmetic talc compared with iodopovidone for chemical pleurodesis. Respirology, 16(7), 1064-1069.

17- Olivares-Torres, C. A., Laniado-Laborín, R., Chávez-García, C., León-Gastelum, C., ReyesEscamilla, A., \& Light, R. W. (2002). Iodopovidone pleurodesis for recurrent pleural effusions. Chest, 122(2), 581-583.

18- Kelly-Garcia, J., Roman-Berumen, J. F., \& Ibarra-Perez, C. (1997). Iodopovidone and bleomycin pleurodesis for effusions due to malignant epithelial neoplasms. Archives of medical research, 28(4), 583-585.

\section{HOW TO CITE}

ELmarghni, J., abdelwahed, E., Sobhy, E., elghamry, W. Povidone-iodine in pleurodesis: it is safe and effective in the management of malignant pleural effusion?. Zagazig University Medical Journal, 2021; 2(219-227): -. doi: 10.21608/zumj.2019.13318.1264 